EMBRYRIDDLE

SCHOLARLY COMMONS
International Journal of Aviation, Aeronautics, and Aerospace

\title{
Aviation Automation and CNS/ATM-related Human-Technology Interface: ATSEP Competency Considerations
}

Adeyinka Olumuyiwa Osunwusi

National Open University of Nigeria, aosunwusi@yahoo.com

Follow this and additional works at: https://commons.erau.edu/ijaaa

Part of the Aviation Commons

\section{Scholarly Commons Citation}

Osunwusi, A. O. (2019). Aviation Automation and CNS/ATM-related Human-Technology Interface: ATSEP Competency Considerations. International Journal of Aviation, Aeronautics, and Aerospace, 6(4).

https://doi.org/10.15394/ijaaa.2019.1390

This Literature Review is brought to you for free and open access by the Journals at Scholarly Commons. It has been accepted for inclusion in International Journal of Aviation, Aeronautics, and Aerospace by an authorized administrator of Scholarly Commons. For more information, please contact commons@erau.edu. 


\section{Aviation Automation and CNS/ATM-related Human-Technology Interface: ATSEP Competency Considerations}

\section{Cover Page Footnote}

*An abridged Microsoft PowerPoint version of this concept paper was prepared for presentation at the 9th Africa Regional Meeting/Conference of the International Federation of Air Traffic Safety Electronics Associations (IFATSEA), NICON Luxury Hotel, Abuja, Nigeria, 5-8 August, 2019. The paper in its present original form, therefore, has not been previously published nor is it before any other journal for consideration. ${ }^{*}$ The author is also an ICAO TRAINAIR PLUS certified Aviation Training Instructor and a Subject Matter Expert (SME) on air traffic safety systems (Communications/ATSEP Basic Competency), Nigerian College of Aviation Technology, Zaria, Nigeria and was, until October 2018, the Training Manager, Directorate of Safety Electronics and Engineering Services, Nigerian Airspace Management Agency, Murtala Muhammed Airport, Lagos, Nigeria. 


\section{Introduction}

The aviation industry has undergone significant transformations ever since December 17, 1903 when the Wright brothers - Wilbur and Orville - made the first powered aircraft flight at Kitty Hawk, North Carolina, USA with their first powered airplane. The industry made even more dramatic changes since September 24, 1929, when Lieutenant General James Harold Doolittle made the first allinstrument "blind flight" in the hooded cockpit of an aircraft while relying entirely on radio navigation, a directional gyro, artificial horizon, and altimeter.

One particularly remarkable hallmark of these dramatic transformations is the frenzied tendencies toward automation, virtualization, and operational/system interoperability. Remarkably, aviation operations are becoming increasingly automated and it is expected that the wind of change sweeping through the industry will be getting stormier as new technologies continue to emerge especially within the context of the emerging prospects of intelligent technologies, which may ultimately enthrone complete automated or technology-based intelligent decision making. As a matter of fact, it has been posited that "artificial intelligence (AI) and machine learning (ML) will be key enablers for advanced functionality and increased automation in the ATM system of tomorrow" (Kistan, Gardi, \& Sabatini, 2018, p. 1).

Understandably, the changes sweeping through the aviation sector are being driven by a plethora of factors, including the increasing growth of air traffic, the growing complexities of aviation operation and its regulatory milieu, the increasing emergence and capability of digital technologies, the increasing need for operational harmonization, air traffic capacity augmentation and system interoperability, and the emerging realities regarding the techniques and technologies for assuring better, more efficient and more sustainable ways of flying. These changes - involving the determined and purposeful integration of new technologies - have resulted in a number of gains, including the increasing availability of the wherewithal for mitigating threats of hazards, the availability of technology for improving facilitation and air passenger experience, and techniques and technologies for reducing personnel workload while improving efficiency and assuring safety and security.

A remarkable characteristic of aviation automation is the pervading nature of the automation typified by the spread of automation across the entire spectrum of the aviation system. Modern-day aircraft carry a wide variety of automated aids such as autopilots, GPS (global positioning system), ACAS (airborne collision avoidance system) and TCAS (traffic collision avoidance system), flight management systems, Flight Directors, and GPWS (ground proximity warning system), which serve to improve the safety and effectiveness of flight operations. 
According to Brown (2016, p. 32), in modern-day cockpits, "automation plays a pivotal role in maximizing safety, efficiency, and sustainability for both the environment and operating costs of airlines." There are also sophisticated computerized reservation systems just as the increasing capability of Radio Frequency Identification Technology (RFID) continues to improve facilitation at airports through revolutionizing automated baggage handling systems and passenger self-service systems. A more contemporary chapter in the annals of aviation automation is the phenomenon of autonomous aircraft - known variously as unmanned aerial vehicles (UAVs), unmanned aircraft system (UAS), remotely piloted aircraft system (RPAS), drones, and so on - which has brought forth the concept of unmanned traffic, the exponential growth of which, in the words of Kistan et al. (2018, p. 1), "is expected to pose its own challenges and produce significant impacts on air traffic management (ATM) with clear consequences on both human-machine systems and infrastructure to support highly automated and resilient/trusted autonomous operations". There is also the question of the sheer imminence of personal aerial vehicles (PAVs) such as air taxis or flying cars.

This paper addresses, based on a systematic review of extant literature, the concept of aviation automation in the context of the broader conceptual and theoretical underpinnings of automation and with an emphasis on automated CNS/ATM systems. The primary aim is to examine the implications of an automated CNS/ATM environment on aspects relating to the tasks, roles, competence, training, certification, and authorization of air traffic safety electronics personnel (ATSEP) - the ICAO-recognized nomenclature for personnel involved and proven competent in the installation, operation, and/or maintenance of a CNS/ATM system. The paper proposes two conceptual models that address ATSEP competencies and ATSEP competency-based task flow in the context of an automation-rich CNS/ATM environment.

\section{Automation in the CNS/ATM Domain}

Traditionally, aviation systems are not only capital intensive but are also profoundly technology-driven. Within this perspective, it can be safely argued that in no sphere of the aviation system has there been, in recent times, a much more lively and sustained exhibition of the spirit of automation than in the realm of communications, navigation, surveillance/air traffic management (CNS/ATM).

As a matter of fact, automation has been identified as being essential to the progressive evolution of the CNS/ATM systems and is also expected to play a commanding role in future development of aviation technology (International Civil Aviation Organization [ICAO], 1994, p. 13). Today, there are increasing 
applications of automation in air traffic safety systems and ANSPs (air navigation service providers) and the growing armies of system manufacturers are the main players in this technology-savvy milieu. This scenario, no doubt, imposes safetycritical obligations on and have wide-ranging implications for the ATSEP in the areas of system operation, maintenance and supervision, competence, training, certification, and authorization. ATSEPs are responsible for installing, commissioning, operating, certifying, and maintaining the CNS/ATM systems that enable air traffic controllers to safely direct and separate air traffic and pilots to safely navigate aircraft.

Citing Billings (1996), Gawron (2019) noted that aircraft automation has been around since 1891 when Sir Hiram Maxim patented the first stability augmentation system, although the "integration of automation began in the early 1960s with systems that aimed at stabilizing the aircraft through a mechanical manipulation of the flight control surfaces" (Dehais, Peysakhovich, Scannella, Fongue, \& Gateau, 2015, p. 2) while the "last big change in the level of automation in aviation was back in the late 1980s, with a shift to today's glass cockpits" (European Commission, 2018, p. 9). In relation to CNS/ATM automation, Hilburn (2002) observed that the widespread use of ATM automation first appeared in the 1960 s, to assist with flight data processing. However, today, there is a wide variety of automated systems in the CNS/ATM realm from electronic data displays and radar data processing to electronic flight strips. Other flavors include:

- Aeronautical Message Handling Systems, involving the transition from the legacy X.25 standard-based AFTN (Aeronautical Fixed Telecommunication Network) and CIDIN (Common ICAO Data Interchange Network) aeronautical messaging systems to the modern and robust X.400 standard-based AMHS (ATS Message Handling System), which uses largely the Internet Protocol for transmission and routing with a messaging framework that is similar to contemporary email messages.

- Aeronautical Information Management (AIM), involving a transition from the product-centric AIS terrain to data-centric AIM operations based on the AIXM model and with the capability to provide, inter alia, automated preflight briefing and NOTAM operations, electronic terrain and obstacles database, digitalized mapping and charting services, and electronic aeronautical information publication (eAIP).

The Aeronautical Telecommunication Network (ATN) concept with its significantly automated ground-ground and air-ground data communication constituents (Context Management-CM, Automatic Dependent Surveillance ADS, Controller-Pilot Data Link Communications-CPDLC, Flight Information Service-FIS, Air Traffic Services Message Handling System-AMHS, and Air 
Traffic Services Interfacility Data Communications- AIDC)) promises to ultimately usher in an era of coordinated and highly interoperable networks of automated ATM systems involving high levels of integration between groundbased and airborne automated aids as well as seamless co-existence in an environment featuring other technologies and capabilities such as GNSS (global navigation satellites system), Area Navigation (RNAV), Required Communication Performance (RCP) and Required Navigation Performance (RNP). Additionally, Mode S transponders, which are predominantly data-link aids, "are already been seen as solution to resolving many ATC problems and difficulties" based on their capability "not only to supply the ATCO with seemingly limitless amounts of data, but also to provide a Conflict Alert and Resolution system for aircraft so equipped" (Ruitenberg, 1999, p. 102).

There are also ATM initiatives, which promise to extend the horizon of air traffic management and ATM automation. These include: SWIM (System Wide Information Management), a global air traffic management initiative and an integral component of the ICAO-driven Global Air Navigation Plan conceptualized for the purpose of facilitating as well as harmonizing the exchange of critical weather, aeronautical, flight and other air traffic management information for all airspace users; NextGen (Next Generation Air Transportation System), a United States' largely satellite technology-based portfolio initiative with capabilities "intended to enable integration of weather, traffic, terrain, and aircraft performance data to enhance safety while reducing delays, fuel requirements, and aircraft emissions" (Dudley et al. 2014, p. 3); SESAR (Single European Sky ATM Research), a technical complement to the Single European Sky initiative launched in 2004, which aims to modernize and harmonize Europe's ATM systems to be more cost-efficient, effective, safer, and environmentally sustainable; CARATS (Collaborative Actions for Renovation of Air Traffic Systems), a Japanese airspace development initiative and a collaborative programme between the Japan Civil Aviation Bureau (JCAB), airlines, airports, and the meteorology office, established in 2010 with the aim of enhancing safety, responding to the increases in air traffic volume, improving operational efficiency, improving user conveniences, and responding to environmental issues; and CNAS (China New Generation ATM System), an integral part of China's long-term air transportation development strategy which takes SESAR and NextGen as references in order to ensure a safe, efficient and environmentally-friendly air transportation system.

There is also the evolving Remote Tower Services (RTS) concept which continues to beckon an ATM future where air traffic control and associated services at an airport are provided from a central but remotely located control tower 
ever since 21 April 2015 when Ornskoldsvik airport, located in the north-west of Sweden, became the first remotely operated airport in the world.

\section{The Conceptual Framework and Nature of Automation}

The term "automation" has been subjected to a wide variety of conceptualizations and definitions, a situation that can be attributed to the growing multiplicity of "automated systems," which, according to the UK Civil Aviation Authority (2016, p. 7), "come in many different forms with a broad scope of system characteristics and capabilities." Sarter, Woods, and Billings (1997, p. 19) pointed to the non-homogeneity of automated systems and argue that these systems not only continue to change "along a number of important dimensions" but also differ significantly as a result of a continuous evolution of technological capabilities "in combination with the different automation philosophies that determine how these capabilities are utilized and implemented."

Thus, the term 'automation' has been conceptualized as referring to: systems or methods in which many of the processes of production are automatically performed or controlled by autonomous machines or electronic devices (Billings, 1996); the process of fully or partially delivering or augmenting a function or service previously carried out by the human (UK Civil Aviation Authority, 2016); the full or partial replacement of a function previously carried out by the human operator (Parasuraman, Sheridan, \& Wickens, 2000), and the replacement of a human function, either manual or cognitive, with a machine function (ICAO, 1994, p. 11).

Billings, in his work titled Human-centered Aviation Automation: Principles and Guidelines, considers "automation" to be:

a tool, or a resource - device, system or method by which a human operator or manager can accomplish some task that would otherwise be more difficult or impossible, or a device or system which the human can direct to carry out more or less independently a task that would otherwise require increase human attention or effort (Billings, 1996, p. 3).

According to the UK Civil Aviation Authority:

the word 'automation' as a noun captures a complex blend of technology interacting with human operators, each carrying out a wide range of tasks, in support of human goals (UK Civil Aviation Authority, 2016, p. 7). 
In the words of Kistan et al (2018, p. 3):

Automation is the ability of a system to perform well-defined tasks without human intervention using a fixed set of "hard-coded" rules/algorithms to produce predictable, deterministic results.

A close examination of the various definitions of the term 'automation' reveals the existence of two strands running through the fabrics of each definition - the human operator or manager, and the tasks. This underscores the overarching importance of the human element irrespective of the levels of automation. It has been posited that an evaluation of the consequences for human operator performance is an important consideration in taking a decision regarding the type and level of automation in any system design (Parasuraman et al., 2000). It has also been argued that because automated systems and aids may fail occasionally, people are necessarily involved as a measure of error recovery and error correction (Bertovic, 2016), thus underscoring not only the human operator as the "common unchanged element in the exponential growth of the automated systems" (Brown, 2016, p. 31) but also the imperativeness of "human-centered automation", an approach which, according to the International Civil Aviation Organization, takes "into account the human element during the design phase so that the resulting system capitalizes upon the relative strengths of humans and computer-based technology" (ICAO, 1994, p. 1).

The concept of human-centered automation is meant to fulfil specific objectives. As Kaber and Endsley (2003, p. 3) have rightly stated: "The goal of human-centred automation is to create systems that retain the human operator in control loops with meaningful and well-designed tasks that operators are capable of performing well in order to optimize overall human-machine system functioning."

As far as the aviation system is concerned, the human components including the cognitive, perceptual and psychomotor skills of human operators are imperative. In relation to the CNS/ATM domain, the ICAO (1994) identified the human element as the key to the successful implementation of the ICAO CNS/ATM concept, which is largely satellite technology-dependent. Humans are also expected, for the foreseeable future, to play a key role in the delivery of ATM and the maintenance support of the technical systems used (UK Civil Aviation Authority, 2016).

Notably, the International Civil Aviation Organization (ICAO) has been very persistent with promoting human-centered aviation system automation philosophy and as succinctly expressed in Part 1, Section 5.2 of the Appendix to 
Chapter 2 of ICAO Doc 9694 (Manual of Air Traffic Services Data Link Applications):

In a complex system, no matter how automated, the human has the last vote in deciding a critical issue and the human is the last line of defence in case of system breakdown.

In relation to the requirements of human-centered aviation system automation, Section 5.4 of the Appendix to Chapter 2, Part 1 of ICAO Doc 9694 states:

Human-centred aviation system automation must be designed and operated in such a way that it does not permit the human operator to become too remote from operational details, by requiring of that operator meaningful and relevant tasks throughout the operation.

The imperativeness of the human being in the loop in a human-automation ensemble can be explained by the contrasts between the human and an automated aid. Automation is designed to operate to strict rules using predefined algorithms, which makes automation unable to take account of new factors or novel situations (UK Civil Aviation Authority, 2016). Humans, however, are intelligent (ICAO, 1994) and more flexible, adaptable, and creative than automation (Parasuraman \& Riley, 1997) and thus are better at taking account of thousands of variables and adapting to novel situations (UK Civil Aviation Authority, 2016). If Lofquist's (2010) characterization of the civil aviation industry as a system "that is highly complex but loosely coupled" while relying heavily on human interaction and being "highly influenced by human variation" were to be viewed as a fundamental truism, then the essence of human-centered aviation system automation can be reasonably explained not only by the contrasts between human and machine but also by the characteristic complexity of civil aviation systems.

Literature reveal a number of principles regarding human-centered automation. Billings, for example, propounded the following nine general guidelines, which he referred to as "the first principles of human-centered automation" (1996, p. 117):

- The human operator must be in command. 
- To command effectively, the human operator must be involved.

- To remain involved, the human operator must be appropriately informed.

- The human operator must be informed about automated systems behavior.

- Automated systems must be predictable.

- Automated systems must also monitor the human operators.

- Each agent in an intelligent human-machine system must have knowledge of the intent of the other agents.

- Functions should be automated only if there is a good reason for doing so.

- Automation should be designed to be simple to train, to learn, and to operate.

With an emphasis on the automation of commercial nuclear-power plants, O'Hara, Higgins, and Barnes (2010) developed the following general principles for human-automation interaction:

- Define the purpose of automation.

- Establish locus of authority.

- Optimize the performance of human-machine team.

- Understand the automation.

- Trust the automation.

- Maintain situation awareness.

- Support interaction and control.

- Minimize workload from secondary tasks.

- Manage failures.

\section{Automation: Benefits, Risks, and Concerns}

Originally, the development of automation technology was pinned on the "hope of increasing the precision and economy of operations while, at the same time, reducing operator workload and training requirements" (Sarter et al. 1997, p. 1). The primary criteria for its application were technological feasibility and cost (Parasuraman \& Riley, 1997), albeit it has been argued that increased autonomy levels cost money and time during the design phase, although, "if implemented correctly, they increase safety and efficiency during the operations phase, which may lead to decreased overall lifecycle costs" (Proud, Hart, \& Mrozinski, 2003, sec. 1).

The desire to automate aviation can actually be tied to five basics needs, namely: the need for enhanced safety (the desire to decrease the frequency of human errors and the need to create a safer approach to meeting future aviation demands); the need arising from the sheer availability of enabling technologies; 
the need for increased operational efficiency and reliability (a more efficient and cost-effective approach to meeting the demands of aviation systems); the need for efficient and technology-enabled operational strategies in response to growing air traffic activities; and the need for improved ways of providing safety-and timecritical information.

Largely, automation has been used to enhance safety, increase productivity, reduce operator workload, and minimize error (Gawron, 2019). Billings (1997, pp. 182-183) highlighted, in relation to flight operations and based essentially on Wiener and Curry's system goals, four demonstrated benefits of automation, namely: safety, reliability, economy and comfort. In relation to CNS/ATM automation, the UK Civil Aviation Authority (2016, pp.11-12) posits that the benefits of ATM automation can be categorized at a high level as providing potential improvements to: safety, efficiency (through reduced cost, increased reliability and consistency), capacity, security, environment, and passenger comfort.

Automation is characteristically evolutionary and time-bound. It is essentially woven into the fabric of modern existence (Tyler, 1999) and has "the capability both to compensate for human vulnerabilities and to better support and exploit human strengths" (National Research Council, 1998, p. 12). Although automation of physical functions has freed humans from many time-consuming and labor-intensive activities (Parasuraman \& Riley, 1997), it, however, introduces a challenge for human-technology integration, creating new human weaknesses and amplifying existing ones (UK Civil Aviation Authority, 2016). Its introduction is almost always attached to a wide variety of expectations that are tied to operational efficiency, human error reduction, cost-effectiveness, reduced personnel workload, increased reliability and so on. However, actual experiences with automated aids have revealed that outputs from automated resources may not perfectly match these expectations in spite of the capability of these aids to monitor and respond to human error. This is particularly true for the aviation system, which has been referred to as consisting "of many variables that are highly dynamic and not fully predictable" (ICAO, 1994, p. 10).

Quite a staggering number of literature (e.g. Bainbridge, 1983; Bertovic, 2016; Billings, 1996/1995; Brown, 2016; Parasuraman \& Riley, 1997; Parasuraman et al., 2000; Sarter et al. 1997; Woods, 2001; has identified and addressed the risks, concerns, and challenges arising from human-automation interactions and the development of automated aids such as a range of technical issues relating to the automation of particular functions and the characteristics of associated sensors, controls, and software (Parasuraman et al., 2000), inappropriate reliance on automation, complacency, and automation bias, which, 
to say the least, are as relevant to the roles of the air traffic safety electronics personnel (ATSEP) as they are to the activities of air traffic controllers and airlines' flight crew. This is more so given the considerable increases in the complexity and level of automation, which create problems of situational awareness. Kaber and Endsley (2003) argued that automated systems, by nature of their complexity, challenge higher levels of situation awareness ("comprehension and projection") "during ongoing system operations."

Literature also revealed a string of problems associated with automation. Gawron (2019) identifies one of the most serious problems as a system failure that forces the operator or user, who has learned to rely on the automated system for crucial decision-making, to suddenly and unexpectedly enter the control loop. This problem has been dubbed "the out-of-the-loop performance problem" characterized by undue delay in detecting a problem necessitating manual intervention after a long period of acting as human "monitor of an automated system" (Endsley, 1996). Wiener and Curry (1980) also listed a number of problems with automation, including automation-induced errors, equipment set-up errors, false alarms, and loss of operator proficiency in the manual mode (cited in Gawron, 2019).

Automation has also been implicated for limiting "the freedom of choice for the individual" and for reducing awareness and alertness (Ruitenberg, 1999). Nickerson (1999) catalogued a number of classical concerns associated with automation, including job destruction, "depersonalization of human services", and job deskilling, which, in the words of the author is "the effect of decreasing the skill requirements of some jobs to the point of making them almost intolerably boring". It appears that Nickerson's classical automation concerns would acquire greater relevance when juxtaposed against Ruitenberg's (1999) argument that automation affects job satisfaction and the exercise of skills and responsibilities when it is extended to problem solving and decision making.

Concerns also surround human factors issues that are rooted in automation, thus raising questions about whether depths of automation implemented are compatible with the capabilities and limitations of human operators. For example, an L-1011 flight crashed into the Florida Everglades in 1972 while the pilots were engrossed with sorting out a landing gear problem and failed to notice a disconnection of an autopilot function (Billings, 1997).

In terms of the severity of the risk arising from automation, literature reveal that the magnitude of the risk is a function of the complexity of automated aids or the level of automation implemented. Bainbridge (1983), for example, suggests that the greater the complexity of automated systems, the greater is the risk to safety consequent upon human error. It has been variously argued that much as 
automation has shaped the behavior of human operators, it, "in some cases, and procedures governing its use in other cases, has impinged on the authority of its operators" (Billings, 1996, p. 5). This reality has been brought out by a number of air accidents, especially the most recent two deadly crashes involving Boeing's state-of-the-art 737 Max 8 aircraft, the cause of which has been laid firmly at the foot of the aircraft's highly automated MCAS (Maneuvering Characteristic Augmentation System).

The risks of inappropriate reliance on automation result from incompatibility between the level of trust in automation and the actual capabilities and limitations of the automated aid. Some of the factors in the development of trust in and reliance on automation include automation reliability (Parasuraman \& Riley, 1997), experience with the automated aid, and individual differences in reliance on automation (Bertovic, 2016). The National Research Council (1998) identified seven attributes of trust in automation, namely: reliability, robustness, familiarity, understandability, explication of intention, usefulness, and dependence.

It has been argued that when accurate and used correctly, relying on automated aids is a very efficient cognitive strategy leading to an accurate and reliable performance of the system while relying on less than perfect aids can lead to errors (Bertovic, 2016). Parasuraman and Riley (1997) also note that operators may not use a reliable automated system if they believe it to be untrustworthy, and they may also continue to rely on automation even when it malfunctions. The consistent reliability of an automated task may have its negative consequence in the risk of complacency, which represents the failure of the human operator to detect system failures due to the consistent reliability of automation. Thus, complacency comes in during repetitive vigilant tasks in which the probability of malfunctions or failures is extremely low.

Bertovic (2016) identified two resultant effects of the risk of inappropriate reliance on automation, namely automation misuse (that is, uncritical reliance on automation resulting from high trust), and disuse, which can result from mistrust (Parasuraman \& Riley, 1997) and which "signifies failures that occur when people reject the capabilities of automation" (Lee \& See, 2004, p. 50). Misuse, which "can result from several forms of human error, including decision biases and failures of monitoring" is an aspect of overreliance on automation (Parasuraman \& Riley, 1997).

The term 'automation bias,' the origin of which Bertovic (2016) linked to Mosier and Skitka, represents, according to Parasuraman and Riley (1997), "a case of inappropriate decision making linked to overreliance on automation" whereby "operators may not sufficiently monitor the inputs to automated systems in order 
to reach effective decisions should the automation malfunction or fail" (Parasuraman and Riley, 1997, p. 240). The term has been defined as a failure to notice problems of the automated aid because of "the tendency to use automated cues as a heuristic replacement for vigilant information seeking and processing" (Mosier \& Skitka, 1996, cited in Bertovic, 2016).

\section{Levels of Automation Taxonomies}

Quite a sizeable number of levels of automation taxonomies has been proposed (e.g. Billings, 1997; Parasuraman et al., 2000; Sheridan \& Verplank, 1978) against the backdrop of the reality that the complexity of automated aids has implications for a wide variety of areas including the level of trust placed on automated systems, the orientation and magnitude of the roles and tasks of human operators, and the magnitude of the risks to safety resulting from human error. This reality raises relevant questions surrounding functions that require automation and the level of automation appropriate for a particular function.

A level of autonomy specifies the degree to which a function or task is automated. It has been argued that "automation is not all or none, but can vary across a continuum of levels from the lowest level of fully manual performance to the highest level of full automation" (Parasuraman et al., 2000, p. 287). What this translates into, as Save and Feuerberg (2012, p. 43) has explained, is that "automation is not only a matter of either automating a task entirely or not, but to decide on the extent of automating it."

Sheridan and Verplank (1978) proposed a taxonomy of levels of automation in man-computer decision-making (see an adapted version in Table 1), which depicts a 10-point decision-making and action-execution interactions scale starting from a fully manual level (Level 1) through to a fully autonomous level (Level 10) in which the automated machine does the whole job without involving the human.

Clearly building on Sheridan and Verplank's 10-point taxonomy and based on a four-stage model of human information processing that incorporates Sensory Processing, Perception/Working Memory, Decision Making, and Response Selection, Parasuraman et al (2000) propose 10 levels of automation of decision and action selection ranging from the lowest, fully manual level where the computer offers no assistance with the human taking all decisions and actions to the highest, fully automated level where the computer effectively ignores the human, decides everything, and acts autonomously. 
Table 1: Levels of Automation in Man-Machine Decision-Making

1. Human does the whole job; the computer offers no assistance.

2. Computer helps to offer alternatives.

3. Computer determines options and recommends an alternative to the human.

4. Computer selects an alternative action.

5. Computer recommends an alternative action and executes it if human approves.

6. Computer executes an action; gives human time to veto action before execution.

7. Computer executes the whole job and informs human of its action.

8. Computer executes action and informs human only if asked.

9. Computer executes the whole job and tells human what it has done only if it decides to.

10. Computer executes the whole job autonomously, ignores the human.

Adapted from Sheridan \& Verplank (1978).

The Levels of Automation Taxonomy (LOAT) developed by SESAR (UK Civil Aviation Authority, 2016) is a much more ATM-specific scale, which addresses specific cognitive functions while taking cognizance of the fact that a technical system has the capability to support multiple cognitive functions. SESAR's LOAT deploys a matrix format that aligns a number of automation levels from level 0 (manual task) through to level 8 (full automation) to four cognitive functions - Information Acquisition, Information Analysis, Decision and Action Selection, and Action Implementation.

\section{CNS/ATM Automation and ATSEP: Implications, Roles, and Tasks}

The significance of 'tasks' in human-technology integration reverberates through almost all the definitions of the term 'automation'. Notably, the heterogeneity and complexity of existing and emerging automated CNS/ATM systems are re-defining not only the roles and tasks of ATSEP but also issues surrounding their competency, certification, and authorization. This viewpoint is further strengthened by the "ironies" (Bainbridge, 1983) and "surprises" (Dehais et al. 2015; Sarter et al. 1997) that characterize automation. In relation to aspects of these ironies and surprises, the ICAO notes that: 
like any other machine, automation is subject to failure. Further, digital devices fail unpredictably and produce unpredictable manifestations of failures. The human's responsibilities include detecting such failures, correcting their manifestations, and continuing the operation safely until the automated systems can resume their normal functions (ICAO, 1999, Part 1, Appendix to Chapter 2, Section 5.3).

The advent of automation and modern technology has not only "created new knowledge and attentional requirements" (Sarter et al., 1997, p. 4) but has also changed the role of the human operator from performing direct manual control to the management of different levels of computer control (Seong \& Bisantz, 1999) or, as Sarter et al (1997, p. 2) has put it, "to one of monitor, exception handler, and manager of automated resources." The complexity and magnitude of this role and the frequency and extent of the human interaction required may not be as considerable for users other than the technical personnel involved in ensuring the effective and reliable operation of automated CNS/ATM systems.

Bainbridge (1983) identified two general categories of task for the human operator in an automated system - that of monitoring to ensure that the automated system is operating correctly, and if not, manually taking over control or calling the attention of a more experienced operator. The direct implication of this is the requirement for the upgrading of human capacity and capability in order to be able to exercise reasonable control over and stay ahead of automated technology in an automation-rich CNS/ATM technical environment. This exerts tremendous demands on assuring and ensuring the development of the competency of ATSEP to be able to resolve problems arising from automation failure aside from raising relevant questions of how much training and retraining are required to perform in an automation-rich environment.

Figure 1 illustrates a proposed competency-based model of ATSEP task flow within the context of an automation-rich CNS/ATM technical environment. Although the model presents a simple illustration of the primary roles of ATSEP in today's rapidly evolving CNS/ATM environment, it should be noted that the tasks, which are essentially interdependent, require for their effective performance well-structured and thoroughly-defined training and retraining strategies built upon effective and regulated certification procedures.

The proposed model depicts ATSEP Task Flow as a core element of a complex human-automation domain that is largely competency-based aside from emphasizing a human-automation interface where the ATSEP will not become so 
reliant on automated systems or so enmeshed in the out-of-the-loop syndrome resulting from extended inactivity to the extent that active participation in terms of active parameter monitoring and control, manual control, and real-time configuration alignment or re-alignment of system control loops is reduced to mere status monitoring. This philosophy engenders the duality of action reflected in the model, namely, the directability and re-directability of actions where the former represents the ability to execute manual control and manipulative tasks targeted at redirecting the automated aid's activities while the latter represents reversion to automation through resetting.

The decision leading to ATSEP action, it should be stressed, should not rest on the use of heuristics in analyzing situations but should emphasize the use of established procedures and troubleshooting checklists. The complexity and trajectory of the manipulative tasks expected from the ATSEP should effectively match the applicable level of automation such that at a reasonably high level of automation, initiating input from the human operator is required for automated functions to be executed. They should also correlate with or match the ability of ATSEP to function, particularly in the event of an operational emergency. This will entail a two-pronged requirement.

The first is that ATSEPs are well grounded on the parameter/status displays and the steps involved in system troubleshooting and automated systems and the positions and tools for their monitoring and control are made as less complex as possible.

Quite a number of researchers have set out to find the correlation between the complexity of system displays and performance and how the presence or otherwise of features in displays of different sizes and complexity impacts performance and mental workload. 


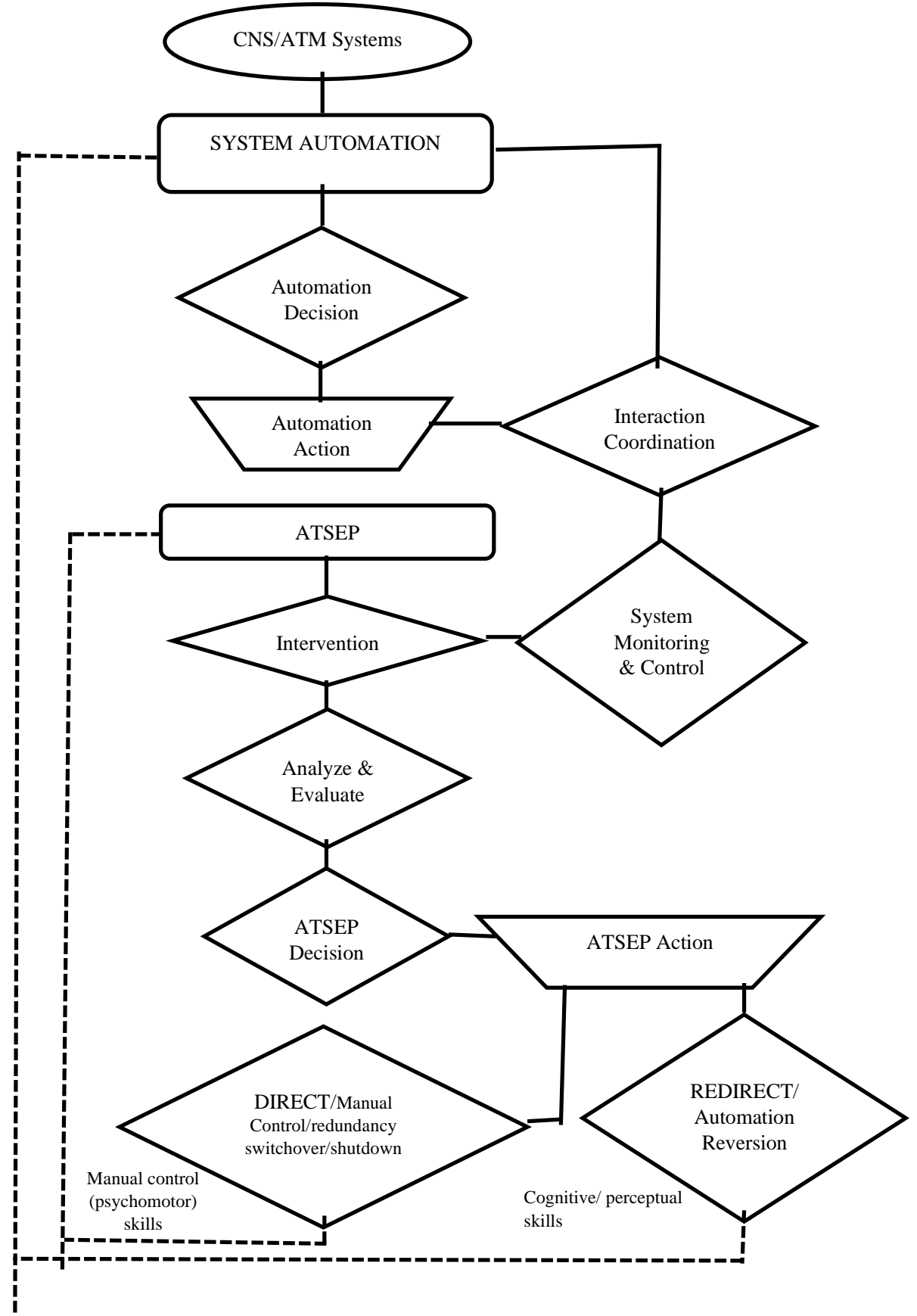

Figure 1: Model Competency-based ATSEP Task Flow in a Human-Automation Domain. 
Literature has shown that monitoring more complex displays or searching among more displays results in decreased performance (e.g. Grubb et al.; Jerison; cited in Schoenfeld \& Scerbo, 1999). However, Schoenfeld and Scerbo's (1999) study found an interaction between feature type and display size with performance being significantly higher in the small as compared to large display size condition, although the decline in performance over time was found to be comparable across display size.

The second requirement relates to what Sarter (1999, p. 222) describes as the "communicative skills of modern technology," that is the ability of modern technology to provide adequate information that will sufficiently guide the human user. In order to address problems emanating from the failure of systems "to complement operators' expectation - or knowledge-driven information search by providing them with external attentional guidance" (Sarter, 1999, p. 222), the author argued for an improvement of "the communicative skills of modern technology" to enable the systems "to play a more active role in sharing information with their human counterparts concerning their status, behavior, intentions, and limitations in a timely manner."

The proposed ATSEP Task Flow model also aligns considerably with the approach proposed by Miller and Parasuraman (2007), which utilized intermediate levels of automation (LOAs) to ensure that neither human nor automation is exclusively in charge of most tasks while ensuring flexibility in the role of automation during system operations such that the exclusive control of that flexibility is placed firmly in the human operator's hands. Woods (2001) qualifies this form of approach, which the author refers to as "intermediate, coordinative modes of interaction", as capable of allowing "human operators to focus the power of the automation on particular sub-problems, or to specify solution methods that account for unique aspects of the situation which the automated agent may be unaware of." In this context, the Monitoring and Control (SMC) task - which may be shared or performed by either the human or the automated aid - is a cooperative effort between the operator and the automated aid, although the dimensions of the SMC tasks depend on organizational designs of SMC functions and the level (s) of automation implemented. Where SMC functions are centralized, the dimensions of SMC functions and the appropriate training and competencies will differ from when functions are decentralized and are largely system- or site specific. 


\section{CNS/ATM Automation and ATSEP: Competency and Certification Considerations}

New technologies will have an impact on operations as well as on existing certification methods and standards (European Commission, 2018). They will also exercise considerable influence on personnel competency and the strategies for inculcating and certifying competency. Competency is defined as "A combination of skills, knowledge and attitudes required to perform a task to the prescribed standard" (Nigerian Civil Aviation Authority, 2015, Part 1, Section 1.5, 165).

The ATSEP Competencies Model illustrated in Figure 2 relates specifically to the ATSEP Task Flow in Figure 1 and emphasizes the need for compatibility between the ability and capacity of the ATSEP to perform in an automation-rich CNS/ATM environment and the ATSEP's roles and responsibility. This translates into the need to adequately associate ATSEP competencies and the training procedures leading thereto with ATSEP's tasks and roles based essentially on the level of automation implemented at a point in time.

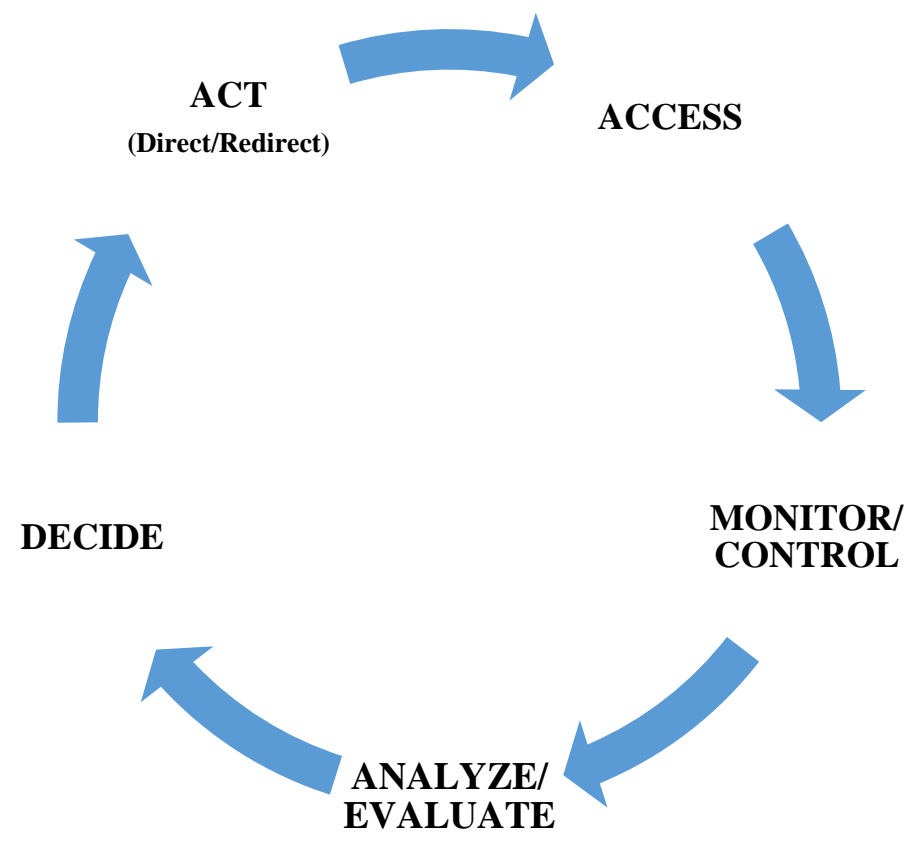

Figure 2: Critical ATSEP Competencies in a Human-Automation Environment.

This need arises from the fact that advances in automation and increases in the level of automation implemented have implications for maintaining hands-on 
currency, with the implication that competency-based trainings and refresher trainings targeted at ensuring ATSEP competency in an automation-rich environment will have to be subjected to periodical reviews as situations may demand.

Table 2 presents a framework that further elaborates the competencies model presented in Figure 2, which also emphasizes the ATSEP's ability to detect and understand a problem requiring prompt human intervention as reinforced by well-defined processes of competency-based training and assessment. Instructions in this respect should embrace a do-it-yourself format designed to reinforce cognitive skills. Competency-based training and assessment is defined as "Training and assessment that are characterized by a performance orientation, emphasis on standards of performance and their measurement, and the development of training to the specified performance standards" (ICAO, 2017, p. ix).

The competencies highlighted in Figure 2 exert greater demands on training and retraining packages that emphasize cognitive and perceptual skills, albeit a building of physical skills is essential for the execution of manipulative tasks. Refresher or recurrent trainings should target bridging the gaps created by degradation of skills consequent upon automation where the system routinely performs tasks requiring such skills. They can also be used, as Sarter et al (1997) suggest, to elaborate the learners' "understanding of how the automation works in a risk-free environment". This means that the trainings should emphasize the reinforcement of cognitive skills as well as human factors competency to raise ATSEP's awareness regarding important elements in the human-automation space.

According to the UK Civil Aviation Authority, user training in the use of automation should include:

- Clarity on the underlying system logic, functions, modes, design assumptions and data fusion.

- How to evaluate the information and solutions provided by the technology in situations where the technology does not recognize the entire operational context.

- How to adapt cognitive and physical work flows to incorporate the information and solutions offered by the technology.

- Tasks and actions required in the event of equipment failures, and to deliver required fallback capability and continuation of service (UK Civil Aviation Authority, 2016, pp. 30-31). 
Table 2: Human-Automation Competency Framework

\begin{tabular}{|c|c|c|c|}
\hline Competency & Objective (s) & Domain (s) & Outline of Indicators \\
\hline Access & $\begin{array}{l}\text { Comprehend and } \\
\text { access system and } \\
\text { system } \\
\text { parameters }\end{array}$ & $\begin{array}{l}\text { Cognitive } \\
\text { skills }\end{array}$ & $\begin{array}{l}\text { Comprehend automated system design } \\
\text { philosophy; comprehend system } \\
\text { redundancy, capabilities and limitations; } \\
\text { understand system's communicative skills; } \\
\text { communicate with system; recognize critical } \\
\text { access points and browse displays; access } \\
\text { specific information/parameters; } \\
\text { comprehend automated systems' operations. }\end{array}$ \\
\hline Monitor/Control & $\begin{array}{l}\text { Active } \\
\text { monitoring and } \\
\text { control tasks }\end{array}$ & $\begin{array}{l}\text { Cognitive/ } \\
\text { perceptual/ } \\
\text { physical skills }\end{array}$ & $\begin{array}{l}\text { Comprehend and react to unusual changes in } \\
\text { system performance indicators; understand } \\
\text { input-output relationships; Comprehend } \\
\text { human-machine relations and human factors } \\
\text { elements (situation awareness); comprehend } \\
\text { and monitor adverse environmental } \\
\text { conditions; comprehend and execute } \\
\text { manipulative actions; monitor execution of } \\
\text { control inputs; verify accuracy of displayed } \\
\text { automated information. }\end{array}$ \\
\hline Analyze/Evaluate & $\begin{array}{l}\text { Effective analysis } \\
\text { and evaluation of } \\
\text { automation }\end{array}$ & $\begin{array}{l}\text { Cognitive/ } \\
\text { perceptual } \\
\text { skills }\end{array}$ & $\begin{array}{l}\text { Perceive system status and analyze effects of } \\
\text { entries; Comprehend system diagnostic } \\
\text { procedures; analyze error messages and } \\
\text { troubleshooting procedures; evaluate } \\
\text { consequences of system } \\
\text { failures/malfunctions; analyze and evaluate } \\
\text { system loggings for performance trends; } \\
\text { predict system performance indicators. }\end{array}$ \\
\hline Decide & $\begin{array}{l}\text { Identification of } \\
\text { appropriate and } \\
\text { safety-driven } \\
\text { control actions }\end{array}$ & $\begin{array}{l}\text { Cognitive/ } \\
\text { perceptual } \\
\text { skills }\end{array}$ & $\begin{array}{l}\text { Comprehend system design philosophy; } \\
\text { awareness of overall ATM operations; } \\
\text { decide on best approach to resolving } \\
\text { problems; identify safe actions and } \\
\text { appropriate procedures; select alternative } \\
\text { actions; decide on extent of coordination } \\
\text { with external stakeholders; decide priorities } \\
\text { of alternatives; decide on form of expert } \\
\text { support required. }\end{array}$ \\
\hline Act & $\begin{array}{l}\text { Take appropriate } \\
\text { control actions }\end{array}$ & $\begin{array}{l}\text { Physical/ } \\
\text { cognitive } \\
\text { skills }\end{array}$ & $\begin{array}{l}\text { Execute chosen control actions; comprehend } \\
\text { effects of control actions; demonstrate } \\
\text { technical knowledge and manipulative skills; } \\
\text { execute fallback procedures. }\end{array}$ \\
\hline
\end{tabular}


The Manual on Air Traffic Safety Electronics Personnel CompetencyBased Training and Assessment (ICAO, 2017) contains prescriptive procedures for the implementation of competency-based training and assessment for ATSEP. These procedures are reinforced by Chapter 3, Part 4 of the Procedures for Air Navigation Services - Training (ICAO, 2015) with provisions for procedures and a flexible framework that training organizations and ANSPs can adopt in line with their local operational contexts and requirements. Given the rapidly changing terrains of ATSEP roles, tasks, training, and competency requirements and the generic nature of the procedures prescribed by ICAO Doc 9868 and Doc 10057, ANSPs and training organizations may need to review the generic framework with a view to creating a framework that will be compatible with operations in an automated environment.

\section{Conclusion}

Automation will, no doubt, be a key determinant of the future of CNS/ATM. As new CNS/ATM automation concepts are developed and deployed for air traffic management, the tasks and roles of ATSEP are expected to change tremendously. Given the safety implications of ATM operations and the realities of automation technology, the reality of the changing role of ATSEP will require the adoption of a philosophical stance that emphasizes flexibility in humanautomation interaction such that the ATSEP can always play an active role in the human-technology ensemble. The transformation of CNS/ATM functionalities as a result of automation will also lead to the creation of new competency, certification, and training requirements that may bring forth questions surrounding whether or not existing training content and techniques match the realities of an automation-rich domain, whether ATSEP trainings adequately reflect an awareness of the philosophies of automation design, and whether existing frameworks for ATSEP competency-based training take cognizance of the complexities and operational realities of different levels of automation, especially the significantly high levels of automation. 


\section{References}

Bainbridge, L. (1983). Ironies of automation. Automatica, 19(6), 775-779. Retrieved from www.ise.ncsu.edu/wp- content/uploads/2017/ 02/Bainbridge_1983_Automatica.pdf/

Bertovic, M. (2016). A human factors perspective on the use of automated aids in the evaluation of NDT data. AIP Conference Proceedings 1706, 020003. https://doi.org/10.1063/1.4940449

Billings, C. E. (1996). Human-centered aviation automation: Principles and guidelines. NASA Technical Memorandum 110381. Moffett Field, CA: NASA Ames Research Center.

Billings, C. E. (1997). Aviation automation: The search for a human-centered approach. Mahwah, NJ: Lawrence Erlbaum.

Brown, J. P. (2016). The effect of automation on human factors in aviation. The Journal of Instrumentation, Automation and Systems, 3(2), 31-46. https://doi.org/10.21535/jias.v3i2.916

Dehais, F., Peysakhovich, V., Scannella, S., Fongue, J., \& Gateau, T. (2015). "Automation surprise" in aviation: Real-time solutions. In Proceedings of the 33rd Annual ACM Conference on Human Factors in Computing Systems, 18-23 April, 2015, Republic of Korea. http://dx.doi.org/ $10.1145 / 2702123.2702521$

Dudley, R., Dorneich, M. C., Letsu-Dake, E., Rogers, W., Whitlow, S. D., Dillard, M., \& Nelson, E. (2014). Characterization of information automation on the flight deck. Proceedings of the Human Factors and Ergonomics Society Annual Meeting, Chicago, IL, October27-31. http://dx.doi.org/10.1177/1541931214581061

Endsley, M. R. (1996). Automation and situation awareness. In R. Parasuraman \& M. Mouloua (Eds.), Automation and Human Performance: Theory and Applications (pp. 163-181). Mahwah, NJ: Lawrence Erlbaum Associates.

European Commission. (2018). Aviation safety - Challenges and ways forward for a safe future (Research and Innovation Projects for Policy). Brussels: European Commission. http://dx.doi.org/10.2777/417337

Gawron, V. (2019). Automation in aviation - Guidelines. Mitre Technical Report MTR190018. McLean, VA: Mitre Corporation.

Hilburn, B. G. (2002). Evaluating human interaction with advanced air traffic management automation. Paper presented at the RTO HFM Symposium 
on 'The Role of Humans in Intelligent and Automated Systems, ' Warsaw, Poland, 7-9 October, 2002. Retrieved from www.sto.nato.int/ publications/.../RTO-MP-088/MP-088-17.pdf

International Civil Aviation Organization. (1994). Human factors in CNS/ATN Systems - The development of human-centred automation and advanced technology in future aviation systems. Human Factors Digest No. 11, ICAO Circular 249-AN/149.

International Civil Aviation Organization. (1999). Manual of air traffic services data link applications (1st ed.) Doc 9694-AN/955. Montreal, Canada: Author.

International Civil Aviation Organization. (2015). Procedures for air navigation services - Training (PANS-TRG) (2nd ed.). Doc 9868. Montreal, Canada: Author.

International Civil Aviation Organization. (2017). Manual on air traffic safety electronics personnel competency-based training and assessment (1st ed.). ICAO Doc 10057. Montreal, Canada: Author.

Kaber, D. B., \& Endsley, M. R. (2003). The effects of level of automation and adaptive automation on human performance, situation awareness and workload in a dynamic control task. Theoretical Issues in Ergonomics Science, 1-40. http://dx.doi.org/10.1080/1463922021000054335

Kistan, T., Gardi, A., \& Sabatini, R. (2018). Machine learning and cognitive ergonomics in air traffic management: Recent developments and considerations for certification. Aerospace, 5, 103. http://dx.doi.org/ 10.3390/aerospace5040103

Lee, J. D., \& See, K. A. (2004). Trust in automation: Designing for appropriate reliance. Human Factors, 46(1), 50-80.

Lofquist, E. A. (2010). The art of measuring nothing: The paradox of measuring safety in a changing civil aviation industry using traditional safety metrics. Safety Science, 48(10), 1520-1529. http://dx.doi.org/ 10.1016/j.ssci.2010.05.006

Miller, C. A., \& Parasuraman, R. (2007). Designing for flexible interaction between bumans and automation: Delegation interfaces for supervisory control. Human Factors, 49(1), 57-75. 
National Research Council. (1998). The future of air traffic control: Human operators and automation. Washington, DC: The National Academies Press. https://doi.org/10.17226/6018.

Nickerson, R. S. (1999). Automation and human purpose: How do we decide what should be automated? In: M. W. Scerbo, \& M. Mouloua (Eds.), Automation Technology and Human Performance: Current Research and Trends. Mahwah, NJ: Lawrence Erlbaum Associates.

Nigerian Civil Aviation Authority. (2015). Nigeria civil aviation regulations. Retrieved from http://www.ncaa.gov.ng/regulations/ncaa-regulations/

O’Hara, J., Higgins, J., Fleger, S., \& Barnes, V. (2010). Guidance for humansystem interfaces to automatic systems. Presented at the 54th Annual Meeting of the Human Factors and Ergonomics Society, San Francisco, CA, September 27- October 1, 2010. Retrieved from https://www.bnl.gov/isd/documents/73919.pdf

Parasuraman, R., \& Riley, V. (1997). Human and automation: Use, misuse, disuse, abuse. Human Factors, 39(2), 230-253.

Parasuraman, R., Sheridan, T. B., \& Wickens, C. D. (2000). A model for types and levels of human interaction with automation. IEEE Transactions on Systems, Man and Cybernetics - Part A: Systems and Humans, 30(3), 286-297. Retrieved from https://hci.cs.uwaterloo.ca/faculty/elaw/ cs889/reading/automation/Sheridan.pdf

Proud, R. W., Hart, J. J., \& Mrozinski, R. B. (2003). Methods for determining the levels of autonomy to design into a human spaceflight vehicle: A function specific approach. Retrieved from https://ntrs.nasa.gov/ archive/nasa/casi.ntrs.nasa.gov/20100017272.pdf

Ruitenberg, B. (1999). Automation and the air traffic controller: Human factors considerations. In: M. W. Scerbo, \& M. Mouloua (Eds.), Automation Technology and Human Performance: Current Research and Trends. Mahwah, NJ: Lawrence Erlbaum Associates.

Sarter, N. B. (1999). Multisensory feedback in support of human-automation coordination in highly dynamic event-driven worlds. In: M. W. Scerbo, M. Mouloua (Eds.), Automation Technology and Human Performance: Current Research and Trends. Mahwah, NJ: Lawrence Erlbaum Associates. 
Sarter, N. B., Woods, D. D., \& Billings, C. E. (1997). Automation surprises. In G. Salvendy (Ed.), Handbook of Human Factors and Ergonomics (2nd ed.). New York, NY: Wiley.

Save, L., \& Feuerberg, B. (2012). Designing human-automation interaction: A new level of automation taxonomy. In: D. de Waard, K. Brookhuis, F. Dehais, C. Weikert, S. Rottger, D. Manzey, S. Biede, F. Reuzeau, \& P. Terrier (Eds.), Human Factors: A View from an Interactive Perspective. Proceedings HFES Europe Chapter Conference, Toulouse. Retrieved from www.hfes-europe.org/wp-content/uploads/2014/06/Save.pdf

Schoenfeld, V. S., \& Scerbo, M. W. (1999). The effects of search differences for the presence and absence of features on vigilance performance and mental workload. In M. W. Scerbo, \& M. Mouloua (Eds.), Automation Technology and Human Performance: Current Research and Trends. Mahwah, NJ: Lawrence Erlbaum Associates.

Seong, Y., \& Bisantz, A. M. (1999). Modeling human trust in complex, automated systems using a lens model approach. In M. W. Scerbo, \& M. Mouloua (Eds.), Automation Technology and Human Performance: Current Research and Trends. Mahwah, NJ: Lawrence Erlbaum Associates.

Sheridan, T. B., \& Verplank, W. L. (1978). Human and computer control of undersea teleoperators (Technical Report). Cambridge, MA: Massachusetts Institute of Technology, Man-Machine Systems Laboratory.

Tyler, R. R. (1999). Human-automation interaction - A military user's perspective. In M. W. Scerbo, \& M. Mouloua (Eds.), Automation Technology and Human Performance: Current Research and Trends. Mahwah, NJ: Lawrence Erlbaum Associates.

UK Civil Aviation Authority. (2016). ATM automation: Guidance on humantechnology integration, Cap 1377. West Sussex, UK: Civil Aviation Authority.

Woods, D. (2001). Human-centered design of automated agents and humanautomation team play. Ohio State University institute for Ergonomics Working Document. Retrieved from www.erogersphd.com/ EMorePages/HRI/HRI-ARCHIVE/woods1.pdf 